\title{
Sequential Design vs. Integrated Design of Blended Learning of Informatics Subject Matter: Is There Any Effectiveness in Developing Cognitive Achievement and Achievement Motivation among Kuwaiti Female Secondary School Students
}

\author{
Hend K. H. Alraghaib1, Abdellatif E. Elgazzar1,2, Ahmed M. Nouby ${ }^{1,3}$ \\ ${ }^{1}$ Distance Learning Department, Arabian Gulf University, Manama, Kingdom of Bahrain \\ ${ }^{2}$ Department of Inst. Technology, Women Faculty, Ain Shams University, Cairo, Egypt \\ ${ }^{3}$ Department of Curricula \& Instruction, College of Education, Suez Canal University, Ismaïlia, Egypt \\ Email: halraghaib@gmail.com, dr.a latif@hotmail.com, ahmednouby2005@yahoo.com
}

Received December 2014

\section{Abstract}

There has been a trend in recent years about discovering the effectiveness of implementing different designs of blended learning, in different learning tasks, different learning outcomes, and for different students. This research aimed at discovering the effectiveness of integrated design and sequential design of blended learning of Informatics Subject Matter in developing female secondary school students' informatics cognitive achievement and achievement motivation-as in the research limitations. Developmental research method was implemented using quasi-experimental two experimental groups design of (22) female students in each group with pre and post tests. Cognitive knowledge aspects were derived through content analysis of the two Units "Advanced Web Concepts" from the Informatics Subject Matter, Instructional design standards list was developed for the two designs, The two blended learning designs were developed through implementing the Elgazzar (2014) ISD model for that Unit in accordance to those standards, two research tools were developed and approved for validity and reliability: Cognitive Achievement test and Achievement Motivation Scale. Research sample of (44) female students was selected and divided to two equal groups and randomly assigned to the research groups according to the specified experimental design. Research experiment was carried out by the first author with the pre and post implementations of the two research tools. Suitable statistical procedures were implemented to test the research hypotheses. Results reveal that there are significant differences at $(\alpha \leq$ 0.05) among means of pre-post Cognitive Achievement test and Achievement Motivation scores of the two groups. Results also reveal that there aren't significant comparative differences between means of posttests of Cognitive Achievement test and Achievement Motivation scores of the two designs of blended learning. So, the answer of the question: Is there any comparative Effectiveness between the two designs in Developing Cognitive Achievement and Achievement Motivation among

How to cite this paper: Alraghaib, H.K.H., Elgazzar, A.E. and Nouby, A.M. (2015) Sequential Design vs. Integrated Design of Blended Learning of Informatics Subject Matter: Is There Any Effectiveness in Developing Cognitive Achievement and Achievement Motivation among Kuwaiti Female Secondary School Students. Open Journal of Social Sciences, 3, 31-39. 
Kuwaiti Female Secondary School Students? Is there isn't any comparative effectiveness. Research report contains Tables, Figures, and References as well as lists of Recommendations and further researches.

\title{
Keywords
}

\author{
Developmental Research Method, Sequential Design of Blended Learning, Integrated Design of \\ Blended Learning, Cognitive Achievement, Achievement Motivation, Secondary School Stage, \\ Informatics Subject Matter, Elgazzar (2014) ISD Model, State of Kuwait
}

\section{Introduction}

Developments in information technology as learning sources have led to the development of the innovations of education technology. E-learning is considered the most important innovations of education technology. It is has a wide range of expansion and a wider range of applications in education and training. E-learning has its methods and strategies and it doesn't grow at random. It is a learning system that is based on the foundations and principles. There are several advantages and potentials of e-Learning in learning - particularly, when it is designed as an integrated e-Learning environment that has elements and components that are work as a whole of communication channels, interaction between students and teachers, collaboration activities, co-operation activities, self or group learning, multiple methods of assessment and evaluation, support systems, and integrity. However, there are many advantages and potentials of traditional/direct learning or face-to-face (F2F) learning, particularly, when practical skills is needed for learning or the learning tasks need hands-on applications. Both potentiality of e-Learning and direct F2F have led designers and policy makers to think of creating new type of learning that combines both advantages. So, designers of educational technology are trying to design a new type of learning that combines the advantages of e-learning and the advantages of traditional direct learning F2F learning, which is the blended learning. Blended learning isn't just a mixture both types of learning, but it is a blend that is based-on many factors such as: the type of learning tasks, design standards, teachers' rolls, available resources, students' characteristics, and the strategies of blending. So, blended learning needs serious researches on its new design variables of blending to insure its effectiveness in learning and training. This current research goes along with this trend of designing blended learning as it is aims at discovering at discovering the effectiveness of integrated design and sequential design of blended learning of Informatics Subject Matter in developing female secondary school students' cognitive achievement (CA) and achievement motivation (AM). There is no need here to discuss CA and AM as learning outcomes from all subject matter in school curricula as well as of learning outcomes of Informatics subject matter curriculum in Kuwaiti Secondary schools. Informatics skills are included as a component of Informatics subject matter curriculum but excluded in this research as being independent variable since authors delimited this research to CA and AM.

There are many benefits and potentials in blended learning. Among its potentials, blended learning is a suitable design for a wide range of learning outcomes of cognitive and performance skills. Easiness of its application, meeting learners' needs and cognitive styles, cost effective, and fitting different educational fields are among benefits of e-Learning [1]. Blended learning has many strategies and models of blending that include but not limited to sequential blending/component blending, integrated blending, co-operative blending, collaborative blending, classroom replacement, e-resource learning centers, flip-classrooms, personalized blending, and expanded blending. Other scholars, Hendawy and Nouby [2] use the term levels to differentiate between types of blending in blended learning carried a study to compare component blended learning to integrated blended learning (two levels of designing blended learning) in the Educational Media Course. Their study have discovered that there is no effects between these two designs on cognitive achievement but there is effect on motivation for the summative blended learning [2]. Logically, it is expected that this result goes for integrated blended learning not for the low level of blended learning as it resulted. So, it has motivated the authors to carry out this research. The current research has focused on two types of blended learning, namely, integrated blended learning and sequential blended learning that are to be designed according new design standards and be developed instructional design model. This research has attempted to discover their effectiveness on developing cognitive achievement (CA) 
and achievement motivation (AM) among secondary school students of Informatics subject matter in the State of Kuwait.

\section{Theoretical Framework of Blended Learning}

Blended learning combines e-learning tools (everything flows through the Internet, from video to e-mail) with training through traditional classroom to ensure maximum effectiveness, where students can prepare and consolidate classroom experiences, online resources, and F2F social interaction with teachers and students in the actual classroom with ease [3]. While Khamis [4] defines it as an integrated learning system that is designed to help the learner through each stage of learning, and is based on a combination of traditional and e-learning in the classroom. Driscoll [5] talks about blended learning that has some combination of educational technology, Internet technology, varied teaching methods derived from learning theories, F2F instructor-led teaching methods, and actual job tasks. So, blended learning in theory is a flexible learning system that combines varied learning resources that includes synchronized or asynchronized Internet and web-based e-Resources, and non e-Resources that includes traditional classroom resources, or F2F teacher and other human learning resources, or laboratory resources, or on-job training resources, or real tasks, or field experiences. These combinations are to be designed according to sound strategies based-on principles/theories of learning, learning/instructional models, and research findings to achieve learning and training outcomes efficiently. This current research is delimited to two blended learning strategies: sequential blended learning and integrated blended learning.

\section{Integrated Blended Learning Design in This Research}

As it has been mentioned in earlier sections, blended learning is to be designed in accordance to a strategy of blending of e-resources and non e-resources. Integrated blended learning is a flexible strategy of blended learning. Integrated blended learning is a level of integration between the sources of information to the learner in the learning environment from one resource provides support to other resource, this type of integrated transfer is considered a common factor among all sources of information transfer Ismaeil [6]. So, this integration mandates designers to keep in their consideration that when selecting a learning resource of information transfer, it will be used for integration with another learning resource of information transfer. This integration can be designed utilizing technological innovations in order to provide references that used by students across all source of information transfer through Links that link the transfer from all sources of information and the resulting of an integration of sources [6]. However, some of these links can be carried out human teacher or learners themselves in the learning environment according to learning/training tasks' requirements. Based on this holistic view of integrated blended learning, an new strategy of blended learning was designed by authors, that is the integration of delivering the Informatics subject matter's knowledge and practical skills through e-resources, individual/self viewing video tapped of informatics skills, student self-evaluation and provision of electronic feedback as well as from teacher, F2F discussions of knowledge and viewed skills with teacher, and then practicing and applying informatics skills practically and electronically (see Figure 1(b) in Arabic). From Figure 1(b), the integrated blended learning takes this sequence: students start with e-learning of knowledge and skills, student views video tapped informatics skill/skills inside classroom/computer lab, student receives immediate electronic feedback on self-assessments from his computer, F2F discussion of knowledge and skills with teacher in classroom/lab, and then practicing and applying informatics skills practically on the computer. Pictures in Figure 1(b), convey steps of this strategy to whom don't know Arabic language.

\section{Sequential Blended Learning Design in This Research}

In comparison to integrated blended learning, sequential blended learning is very much simpler in its design. It is considered a timeline summation of e-Learning resources and non e-Learning resources without any concern to any integration between sources of information to the learner to the learner in the learning environment other than the linear flow of information from one resource to the subsequent resource in the timeline. Sequential blended learning combines multiple knowledge sources to the learner depends on: student characteristics, nature of learning process, available learning resources, and information technology infrastructure in the institution [6]. So, the key element in designing sequential blended learning is the summation of separated sources of knowledge delivered in timeline/linear flow of information to the learner. Based on this view of sequential blended 


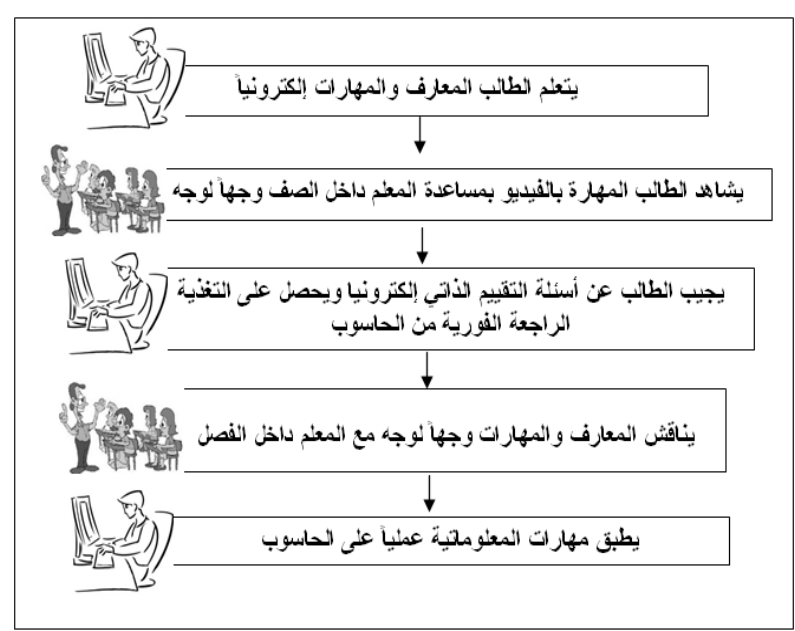

(a)

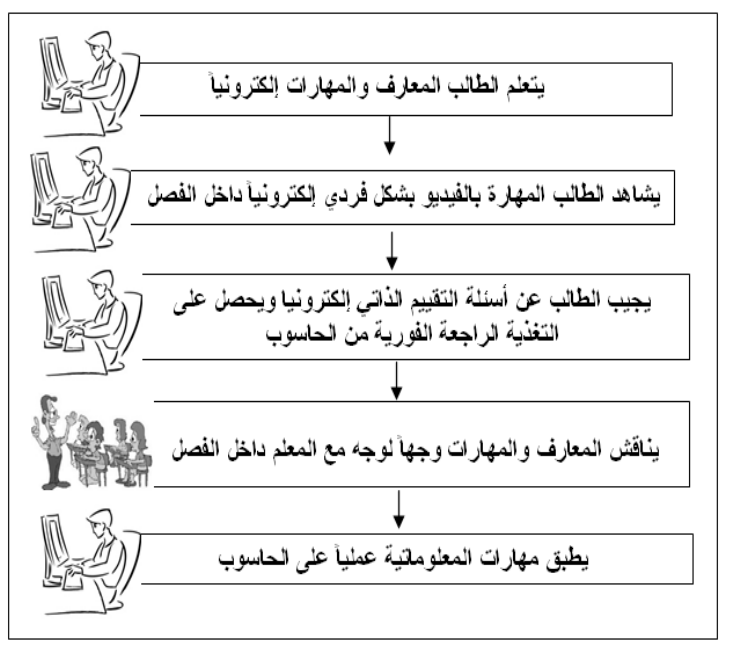

(b)

Figure 1. Sequential (a) \& Integrated (b) Blended learning strategy as of this research.

learning, an new strategy of sequential blended learning was designed by authors, that is the linear summation of delivering the Informatics subject matter's knowledge and practical skills through e-resources, F2F viewing video tapped of informatics skills, student sef-evaluation and provision of electronic feedback as well as from teacher, F2F discussions of knowledge and viewed skills with teacher, and then practicing and applying informatics skills practically and electronically (see Figure 2L in Arabic). From Figure 2L, the sequential blended learning takes this sequence: students start with e-learning of knowledge and skills, F2F viewing video tapped informatics skill/skills inside classroom/computer lab, student receives immediate electronic feedback on self-assessments from his computer, F2F discussion of knowledge and skills with teacher in classroom/lab, and then practicing and applying informatics skills practically on the computer. Pictures in Figure 2L, convey steps of this strategy to whom don’t know Arabic language.

\section{ISD Model for Integrated/Sequential Blended Learning Designs}

Designing integrated blended learning and Sequential Blended Learning should be systematically done. That is due to nature of this research. Authors reviewed available ISD models that can be implement in this developmental research. A most recent ISD model of the second author was selected [7] for designing both designs according to ISD standards and to allow for delivering these designs from an e-learning environment for better learner management and control. This Elgazzar (2014) ISD model is shown in Figure 2.

\section{Research Problem Statement and Questions}

The research problem has been stated as "there is a noticed low level of both cognitive achievement and achievement motivation among female secondary school students in Informatics subject matter, and there is a need to discover effects of two designs of blended learning on developing their cognitive achievement and achievement motivation”. So, the main question that has to be answered: Is there any effectiveness integrated blended learning design vs. sequential blended learning design in Developing both cognitive achievement (CA) and achievement motivation (AM)? Five sub-questions have been derived:

1. What are the cognitive content components (knowledge and cognitive skills) for students to achieve from Informatics subject matter?

2. What are the design standards of the two blended learning designs: integrated and sequential programs?

3. What are the two programs: integrated blended learning (IBL) and sequential blended learning (SBL) according those standards using Elgazzar (2014) ISD model [7]?

4. How effective is the implementation of these two designs: IBL and SBL in developing cognitive achievement (CA)?

5. How effective is the implementation of these two designs: IBL and SBL in developing achievement moti- 


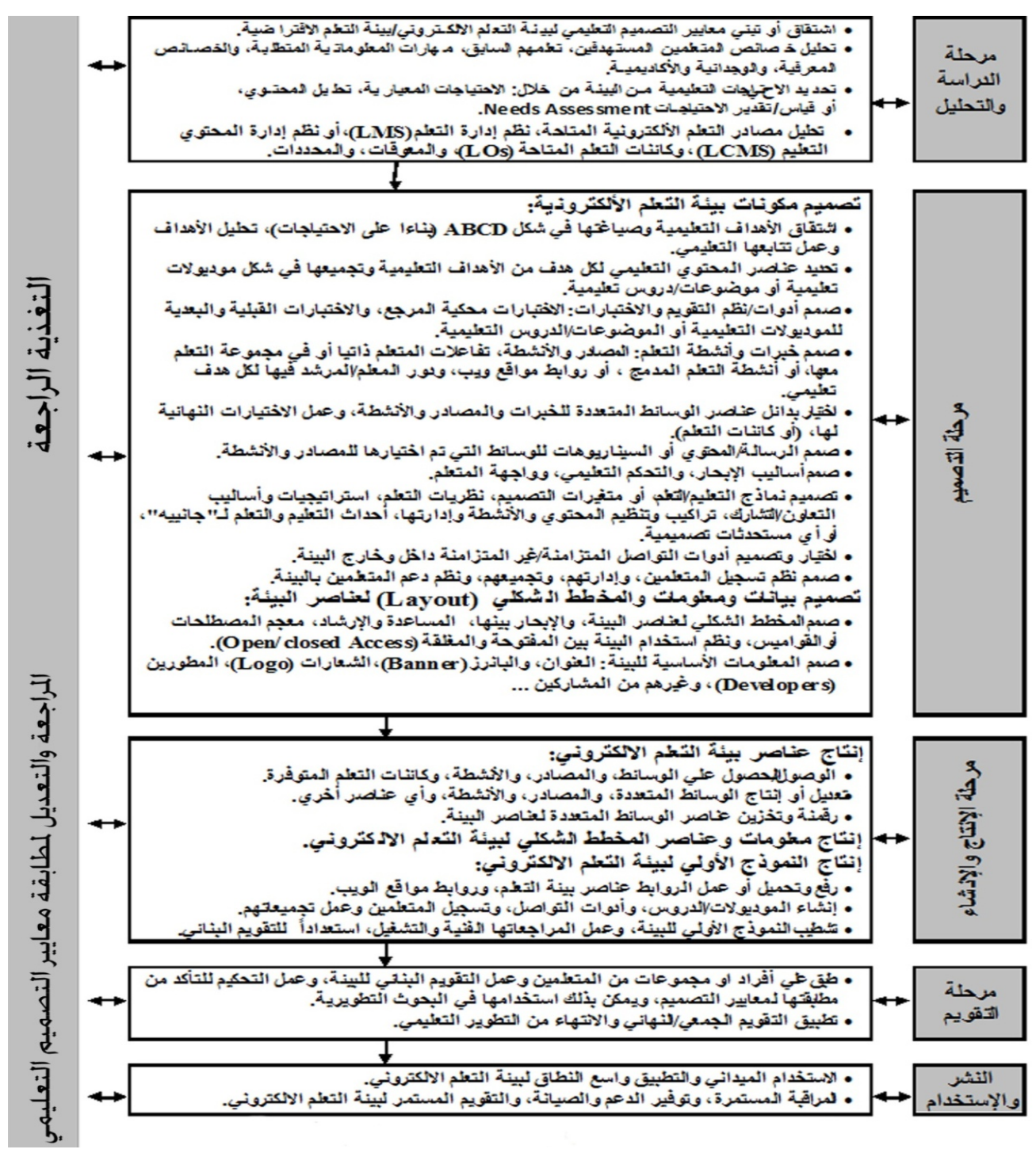

Figure 2. Elgazzar (2014) ISD model as used in this research (Arabic Version).

vation $(\mathrm{AM})$ ?

\section{Research Method}

The Developmental Research Method as described by Elgazzar [7] was used in this research. This research method combined three integrated research methods were used:

1) Descriptive research method implemented in students' characteristic analysis, course content analysis, resources analysis, and establishing design standards list of blended learning designs,

2) Systems Development Method in terms of implementing Elgazzar ISD Model [7] in developing the two designs IBL and SBL according to standards.

3) Experimental research method in the research experiment to investigate the comparative effects of the two designs IBL and SBL in developing female students’ cognitive achievement (CA) and (AM).

\section{Research Procedures}

\subsection{Content Analysis of Informatics Subject Matter (Approximately Two Units)}

Content analysis of the two Units “Advanced Web Concepts and Building a Flash Website” of Informatics sub- 
ject matter as it is required to Elgazzar ISD model (2014) to find out knowledge and cognitive skills that are to be achieved. Content analysis has resulted in (33) components of knowledge and cognitive skills. The content analysis components' list was refereed. This list was used to derive instructional needs, instructional objectives, and the cognitive achievement test. So, the first sub-question has been answered.

\subsection{Deriving IBL and SBL Programs Instructional Design Standards}

A primary list of instructional design standard and their indicators was established based-on content analyses of learning content in (8.1), IBL and SBL design characteristics, and phases of Elgazzar (2014) ISD Model. This primary list of standards and their indicators was subjected for refereeing from (18) experts. The final most agreed upon list of standards and their indicators became (13) standards and (70) of their indicators. So, the second sub-question has been answered.

\subsection{Developing the IBL and SBL Program Designs}

As it has been mentioned in earlier section, the Elgazzar (2014) ISD model was selected for developing the two treatment programs of blended learning: IBL and SBL according to the derived standards. A very lengthy details of developmental tasks were done on applying Elgazzar ISD Model (2014) in Figure 2 (Arabic Version) until the two IBL and SBL program designs were approved to meet ISD design standards derived in (8.2). The $1^{\text {st }}$ author carried out this section. These detailed developmental tasks have been described in Alraghaib [8]. The phases of the ISD model were applied by the $1^{\text {st }}$ author till the formative evaluation and the approval of the two designs of blended learning: IBL and SBL met the ISD design standards. Then the two IBL and SBL were uploaded to the virtual learning environment (VLE) of MOODLE along with F2F extra materials. So, the third sub-question has been answered and the two designs: IBL and SBL were ready to be implemented In research experiment.

\subsection{Participants and Experimental Design}

The final sample size was (44) female students of two classrooms from two schools, one classroom from each school. So, the research sample of this research was a purposive clustered sample form two schools from the Capital District in Kuwait. This sample was divided and assigned randomly into two experimental groups of (22) students each. The two experimental groups with pretest-posttest Quasi-Experimental Design was used. The $1^{\text {st }}$ experimental group was assigned to SBL design program, while the $2^{\text {nd }}$ experimental group was assigned to IBL program.

\subsection{Research Tools}

Two research tools were developed: a Cognitive Achievement Test (CAT) and an Achievement Motivation Scale (AMS) for this research. The CAT was built on learning objectives and was consisted of (57) items, in varied forms of objective test items on Informatics cognitive components from content analyses in (8.1). The AMS was derived from from other achievement motivation scales with adaptation to Informatics and consisted of (41) five level Likert scale items. CAT and AMS content validity were done through refereeing by specialists in the field of educational technology and psychology. The reliability of the CAT and AMS was carried out on their pretests data, the calculated Cronbach's Alpha $(\alpha)$ coefficient for CAT was $(\alpha=0.83)$ and for AMS was $(\alpha=$ 0.89). These values of the reliability the CAT and AMS showed highly acceptable tools. So, CAT and AMS became valid and reliable tools for the purpose of this research.

\subsection{Experiment of the Research}

The experiment of the research took place in Kuwait. So, the 1st author carried out the implementation of the two IBL and SBL program designs during the second semester of the year 2013-2014 according to the experimental design. Experimental group 1 studied using the SBL program while Experimental group 2 studied using the IBL program. The experiment lasted about five weeks: three weeks for the three modules, and two weeks pre-testing and post-testing. Pre-testing and post-testing of both CAT and AMS were implemented.. Data was collected and coded to the SPSS Package. 


\section{Results and Discussions}

Descriptive statistics of research groups: SBL program design and IBL designs have been calculated and presented in Table 1. It is so clear from data that students in SBL design has the mean of the post-test scores of CAT of (22.59) which is greater than that of IBL of (18.00), moreover, the mean score of posttest of AMS of SBL design (131) is greater than that of the mean score of AMS of the IBL design of the value (124.18). It was expected that the higher the level of blending, the better the performance. So, these noticeable differences are not expected, female students studied through SBL design program got higher performance in cognitive achievement of informatics than those studied through IBL program design. This result is interpreted only if the female students' cognitive styles affected their learning from IBL design. In other words, they learn more in linear sequence of learning resources better than integrated learning resources as in IBL design. However, these differences among means might not be significant. On the other hand, when comparing means of pretests' scores and their posttests' scores, both designs are effective on developing cognitive achievement (CA) of informatics, but not in achievement motivation.

To answer the fourth and fifth sub-questions and, two hypotheses were formulated and tested.

Hypothesis (1): There are significant differences at level $(\alpha \leq 0.05)$ between the two means the SBL design and IBL design of blended learning in posttest of CAT and in posttest of AMS for IBL design of blended learning.

To test hypothesis (1), the independent samples t-test was applied to test the significance of the differences between means of the posttest scores of CAT and AMS scores. As it is seen in Table 2, the t-value (3.26) of the two means difference of CAT $(22.59,18.00)$ at $\mathrm{df}(42)$ is significant at $(0.05)$ since the computed significance $(0.00<0.05)$ but not for IBL. Also, the t-value $(1.45)$ of the two means difference of AMS $(131,124.18)$ at $\mathrm{df}$ (42) is not significant at $(0.05)$ since the computed significance $(0.16>0.05)$. So, Hypothesis $(1)$ is partially rejected for the difference between the two means of the posttest of achievement motivation scale (AMS). The most important result hear is that the significant difference goes for favoring SBL design of blended learning which is the opposite of what was expected. However, this significant difference may be it is due to the effect of pretest scores of CAT not from the effect of the difference between the two designs: SBL vs. IBL.

To make sure that resulted difference between the two SBL and IBL designs in the two means of posttest of CAT and AMS aren't due to differences in both pretests of CAT and AMS, another Hypothesis (2) was formulated and tested to check the significance of differences between means of posttests of CAT and AMS when pretests' scores of CAT and AMS are controlled.

Table 1. Means and standard deviations for the two SBL and IBL program designs of research variables.

\begin{tabular}{ccccc}
\hline & \multicolumn{4}{c}{ Blended learning program designs } \\
\cline { 2 - 5 } Research variables & \multicolumn{2}{c}{ SBL design (22) } & M & IBL design (22) \\
\cline { 2 - 5 } & 22.59 & SD & 18.00 & 4.85 \\
\hline Posttest of CAT & 16.37 & 4.48 & 8.64 & 7.15 \\
Pretest of CAT & 131 & 14.6 & 124.18 & 16.54 \\
Posttest of AMS & 136 & 15.73 & 124 & 18.37 \\
Pretest of AMS & & & & \\
\hline
\end{tabular}

Table 2. Independent t-tests' results of the means’ differences between SBL and IBL of post-tests scores of CAT and AMS.

\begin{tabular}{|c|c|c|c|c|c|c|c|}
\hline Test scores & Group & $\mathbf{N}$ & $\mathbf{M}$ & SD & $\mathbf{t}$ & $\underline{\text { df }}$ & significance \\
\hline \multirow[t]{3}{*}{ Posttest CAT } & SBL & 22 & 22.59 & 4.48 & 3.26 & 42 & 0.00 \\
\hline & IBL & 22 & 18.00 & 4.85 & & & \\
\hline & SBL & 22 & 131 & 14.6 & 1.45 & 42 & 0.16 \\
\hline Posttest AMS & IBL & 22 & 124.18 & 16.54 & & & \\
\hline
\end{tabular}


Hypothesis (2): There are significant differences at level $(\alpha \leq 0.05)$ between the two means of the SBL and IBL designs of blended learning in posttest scores of CAT and AMS when controlling the pretest scores of CAT and AMS. Authors applied the One-Way ANCOVA to test Hypothesis (2). Table 3 shows results of the two tests: CAT (Cognitive Ach.) and AMS (Ach. Motivation). From the upper half of Table 3, the F-value (1.34) of the main effect of between designs (SBL and IBL) at df $(1,41)$ is not significant at $(0.05)$ since the computed significance $(0.25>0.05)$, so, Hypothesis (2)is rejected for the variance for CAT. From the lower half of Table 3 , the F-value (1.47) of the main effect of between designs (SBL and IBL) at df $(1,41)$ is not significant at $(0.05)$ since the computed significance $(0.23>0.05)$, so, Hypothesis (2)is rejected for the variance for AMS. So, Hypothesis (2) is rejected to confirm that significant difference between the two means of CAT of the two designs: SBL and IBL in Hypothesis (1) is due to effects from pretest scores of CAT. In other words, it is due to effects from the pre-entry levels of students in CAT scores and the relation that might exist between pretest and posttest of CAT. So, the fourth and fifth question have been answered.

These results reveal that the comparative difference between both SBL design and IBL design isn't significant even after controlling the effects of the pretests' scores of CAT and AMS as covariates in the ANCOVA model. It is clearly shows that the variation between sequential design of blended learning and integrated design of blended learning of Informatics Subject Matter's learning doesn't have any comparative effects in developing both cognitive achievement and achievement motivation among Kuwaiti Female Secondary School Students. This gives the answer to the main question of this research. This final result is similar to the results revealed by of Hendawy and Nouby [2] that integrated design of blended learning and sequential design both have impact effects on developing cognitive achievement and achievement motivation as seen between pretest and posttests but no comparative effects. An interpretation to this final result is tha it is due to female students' characteristics such as cognitive styles, or due to the nature of Informatics' learning. However, a comparative effect between SBL and IBL designs of blended learning may be found in other learning outcomes of Informatics such as problem solving, systematic thinking skills, or performance skills.

\section{Research Recommendations}

Based on these findings of the research, the following practical recommendations can be driven:

1) The list of instructional design standards of SBL and IBL blended learning which developed in this research should be adopted by researchers and e-Learning. Developers in e-Learning and distance learning centers.

2) These two developed SBL and IBL of blended learning should be used in improving Informatics learning in Secondary School Curriculum of Informatics in the State of Kuwait.

3) The instructional design model of Elgazzar (2014) should be used in developing blended learning and other e-Learning resources.

\section{Future Researches}

The following future researches are suggested:

Table 3. One-Way ANCOVA results of posttests of CAT and AMS with pretests of CAT and AMS as covariates.

\begin{tabular}{|c|c|c|c|c|c|c|}
\hline ANCOVA & Source Of Variance & SS & df & MSS & $\mathbf{F}$ & significance \\
\hline \multirow[t]{4}{*}{ Cognitive Ach. } & Pretest of CAT & 167.19 & 1 & 167.19 & 9.16 & 0.00 \\
\hline & Between designs & 24.46 & 1 & 24.46 & 1.34 & 0.25 \\
\hline & Error & 648.13 & 41 & 18.25 & & \\
\hline & Total & 19271.00 & 44 & & & \\
\hline \multirow[t]{4}{*}{ Ach. Motivation } & Pretest of AMS & 7997.71 & 1 & 7997.71 & 147.20 & 0.00 \\
\hline & Between designs & 79.99 & 1 & 79.99 & 1.47 & 0.23 \\
\hline & Error & 2227.56 & 41 & 54.33 & & \\
\hline & Total & 727032.00 & 44 & & & \\
\hline
\end{tabular}


1) Studying the effects of designing blended learning on developing higher cognitive skills such as problem solving skills, systematic thinking skills, and creative thinking skills among female students as well as male students.

2) Using developmental research method in as defined by Elgazzar [6] in research of educational technology, e-Learning, and distance learning.

3) A fellow-up of the effects of designing SBL and IBL of blended learning on developing Informatics performance skills among female students as well as male students.

4) Studying the effects of the interaction between these two SBL and IBL designs of blended learning and cognitive styles on developing Informatics cognitive achievement, performance skills, attitudes, achievement motivation, and deep learning.

\section{Acknowledgements}

This research has been done as a part of King Hamad Academic Chair of eLearning activities, Distance Learning Dept., Arabian Gulf University. The authors are deeply giving special thanks to Arabian Gulf University for supporting them to attend the CITE 2015. Special thanks go also to CITE 2015 for honoring Prof. Elgazzar-the second author-Chairing the CITE 2015 Conference session, Shanghai, China.

\section{References}

[1] Wilson, D. and Smilanich, E. (2005) The Other Blended Learning. A Classroom-Centered Approach. Pfeiffer, San Francisco.

[2] Hendawy, O.S. and Nouby, A.M. (2010) Effect of Varying Blending Level of Learning Resources Used in Blended Learning on Achievement and Motivation towards Learning. Journal of Education, Scientific Refereed Journal, Faculty of Education, Al-Azhar University, Cairo, No. 144(2), 419-476. (ARABIC).

[3] Marsh, J.E. (2001) How to Design Effective Blended Learning. www.brandon-hall.com

[4] Khamis, M.A. (2003) Instructional Technology Outputs (Mantogate). Dar Alkalema Puplishing, Cairo. (ARABIC).

[5] Driscoll, M. (2002) Blended Learning: Let’s Get beyond the Hype. IBM Global Services. http://www-07.ibm.com/services/pdf/blended_learning.pdf

[6] Ismaeil, A.Z. (2009) E-Learning from Application to Professionalism and Quality. Alam El-Kotob Puplishers, Cairo. (ARABIC).

[7] Elgazzar, A.E. (2014) Developing E-Learning Environments for Field Practitioners and Developmental Researchers: A Third Revision of an ISD Model to Meet E-Learning and Distance Learning Innovations. Open Journal of Social Sciences, 2, 29-37.

[8] Alraghaib, H.K.H. (2014) Sequential and Integrated Designs of Blended Learning and their Effectiveness in Skills and Achievement Motivation among Kuwaiti Secondary School Students. MA Thesis, Arabian Gulf University, Manama, Kingdom of Bahrain. 